\title{
ANIMALESCOS, O BESTIÁRIO CONTEMPORÂNEO DE GONÇALO M. TAVARES ${ }^{1}$
}

\author{
Rosana Cristina Zanelatto Santos*
}

RESUMO: Considerado um gênero literário medieval, o bestiário descrevia física e comportamentalmente animais reais ou imaginários, atribuindo cunho moralizante ao quadro representado. Era escrito em prosa ou versos, sendo ilustrado e tomando a natureza ao modo cristão de ver o mundo, isto é, como fonte de ensinamento para o ser humano, demonstrando-lhe, por vezes, seu parentesco não somente biológico com o animal. Com o distanciamento do universo secular dos dogmas cristãos, os bestiários perdem sua força como gênero, e os animais de suas páginas migram para a iconografia eclesiástica e, mais tarde, para as artes visuais, valendo citar, por exemplo, a relação visual entre homens e animais na obra de Goya. Nossa pretensão é demonstrar que Animalescos, de Gonçalo M. Tavares, agrega-se ao gênero bestiário, que não desapareceu, porém, ganhou novos contornos com o passar dos tempos. Se na ficha catalográfica da edição brasileira (Dublinense, 2016) lemos que se trata de "contos portugueses", discordamos dessa rubrica, uma vez que há um fio temático - a perversidade - que alinhava as narrativas, alicerçadas sobre relações entre homens, animais, cidades, máquinas, neuroses, violência e morte.

PALAVRAS-CHAVE: Bestiário; Gêneros Literários; Aberto; Literatura Portuguesa.

Os homens seriam em princípio esses viventes que se deram a palavra para falar de uma só voz do animal e para designar nele o único que teria ficado sem resposta, sem palavra para responder.

(DERRIDA, 2002, p. 62)

A pretensão precípua deste breve estudo é demonstrar que Animalescos, de Gonçalo M. Tavares, agrega-se ao gênero bestiário, que não desapareceu, porém, ganhou novos

\footnotetext{
${ }^{1}$ Este ensaio se inscreve no bojo do projeto de pesquisa "Historiografia e cânone: o perverso, o abjeto, o animal" (Edital Universal FUNDECT), que conta com pesquisadores da UFMS, UEMS, UnB, UFPel e UFAC.

* Doutora em Letras (Literatura Portuguesa) pela Universidade de São Paulo (Usp). Professora Titular da Universidade Federal de Mato Grosso do Sul (UFMS).
} 
contornos com o passar dos tempos. Se na ficha catalográfica da edição brasileira de Animalescos (Dublinense, 2016) lemos que se trata de "contos portugueses", discordamos dessa rubrica naquilo que ela carrega de estreitamento de horizontes em relação ao que se entende por conto, ou seja, uma noção cristalizada dentro dos estudos literários acerca dos limites organizacionais desse e de outros gêneros. As narrativas (com)postas nessa obra de Tavares estão unidas por um fio temático - a perversidade tomada no seu sentido lato de corrupção, de desvio de um rumo proposto - que as alinha de modo até didático (aqui pensamos em uma didática geral, que não se atém a este ou àquele procedimento formal, nem a qualquer orientação pedagógica específica), alicerçadas sobre relações entre homens, animais, cidades, máquinas, neuroses, violência, melancolia e morte.

Comecemos esclarecendo o que entendemos por bestiário. Considerado um gênero literário medieval, o bestiário descrevia física e comportamentalmente animais reais ou imaginários, atribuindo cunho moralizante ao quadro representado. Era escrito em prosa ou versos, sendo ilustrado e tomando a natureza ao modo cristão de ver o mundo, isto é, como fonte de ensinamento para o ser humano, demonstrando-lhe, por vezes, seu parentesco não somente biológico com o animal. Com o distanciamento do universo secular dos dogmas cristãos, os bestiários perderam sua força como gênero didático e literário, e os animais de suas páginas migraram para a iconografia eclesiástica e, mais tarde, para as artes visuais, valendo citar, por exemplo, a relação visual entre homens e animais na obra de Goya, em uma matriz cuja tônica não é mais o parentesco direto do humano com Deus, porém, com aquilo que, de modo raso, o animal tem de mais feroz.

Questionamo-nos, neste ponto, sobre a natureza humana. Qual é/seria ela? Há várias evidências sobre essa natureza e ao menos duas delas permeadas pelo animal: a de Lineu $^{2}$, que em seu Systema Naturae classifica o homem na ordem os primatas, numa (re)afirmação da origem divina das criaturas, e a de Buffon, para quem o animal está no outro, aquele em quem nos reconhecemos como corpo (por exemplo, o orangotango), porém ao

2 Sobre ele e sua proposição nos deteremos mais adiante. 
qual somos superiores, pela razão, pela liberdade e por outras condições (MARZANO, 2012, p. 703-707). Uma terceira esforça-se em distanciar o homem de sua natureza (também) animal:

\begin{abstract}
Se a ideia de uma história natural comum a todos os animais pouco a pouco se impôs, a preocupação em marcar a característica excepcional do homem permanece muito forte. Quem enfatiza a natureza animal do homem sem logo conceder que, bem entendido, o homem não se poderia resumir a ela é tachado de reducionista. A natureza humana não poderia se reduzir à natureza. (MARZANO, 2012, p. 704)
\end{abstract}

Apesar de algumas contendas cujo cerne se debate (ainda) sobre questões como as acima delineadas, o (ser) humano “[...] não é definível em termos de essência ou de 'natureza’ representada por um tipo único. A espécie é um conjunto de corpos que têm pontos em comum, mas também diferenças” (MARZANO, 2012, p. 705), que podem ser biológicas, de gênero, étnicas, culturais, psicológicas e outras tantas.

Se o arrefecimento das ideias criacionistas propiciou perspectivas como as de Sartre, para quem o homem é o que faz de si/consigo mesmo, no campo literário/artístico os embates sobre a animalidade humana continuam em curso. Voltemo-nos, pois, novamente para a literatura dos bestiários.

Talvez um dos últimos escritores do século XX a denominar/a confessar um conjunto de poemas como bestiário, ao lado de Julio Cortazar, tenha sido Guillaume Apollinaire. ${ }^{3}$ A primeira edição veio à luz em 1911, sendo intitulada Bestiário ou cortejo de Orfeu. A recepção crítica dos poemas do Bestiário durante muito tempo qualificou-os como sendo um conjunto poético menor em relação aos demais textos de Apollinaire, o que nos traz à lembrança o ensaio de Deleuze e Guattari Kafka: por uma literatura menor.

\footnotetext{
${ }^{3}$ Em tempo: bestiários continuam a ser escritos, porém, a expressão "bestiário" é que parece marcada por um pré-conceito que acaba por limitar seu uso. O que se veem são narrativas como o Manual de zoofilia fantástica, de Jorge Luís Borges, e o Manual de zoofilia e Jardim Zoológico, ambos de Wilson Bueno, para ficarmos na América Latina.
} 
Uma das assertivas de Deleuze e Guattari (2015, p. 35), logo no início do capítulo 3, “O que é uma literatura menor?”, esclarece que: "Uma literatura menor não é a de uma língua menor, mas antes o que uma minoria faz em uma língua maior". Ou seja, o uso que sujeitos considerados menores dentro de uma determinada sociedade, seja por suas condições políticas, socioeconômicas, ou culturais, fazem de uma dada língua, é trazido à tona pela tal literatura menor, desestabilizando - para Deleuze e Guattari, desterritorializando os agenciamentos subscritos pelos donos do poder, inclusive em termos literários. A língua então passa a ser instrumento do sentido - e aqui o sentido tem via de mão dupla: é o que se sente/o que nos afeta e o que transfiguramos a partir daquilo que nos é dado a conhecer sonoramente pela palavra.

Se a leitura de Deleuze e Guattari mira a presença/a permanência da literatura de Kafka em face de circunstâncias de produção nada positivas - ser judeu em Praga e ter que escrever em alemão -, ela também nos enseja a pensar nos bestiários, por meio das referências a animais como o cão e um rato:

Escrever como um cachorro que faz seu buraco, um rato que faz sua toca. E, para isso, achar seu ponto de subdesenvolvimento, seu próprio dialeto, seu próprio terceiro mundo, seu próprio deserto. Houve muitas discussões sobre: o que é a literatura marginal? [...] Os critérios são evidentemente muito difíceis, enquanto não se passe por um conceito mais objetivo, o de literatura menor. É somente a possibilidade de instaurar de dentro um exercício menor de uma língua mesmo maior que permite definir literatura popular, marginal, etc. (DELEUZE; GUATTARI, 2015, p. 39)

Tanto o cão quanto o rato não constroem o buraco e a toca tão somente como lugares de fuga. Eles são, sobretudo, lugares de (re)acolhimento/proteção. Ambos os lugares também nos (re)conectam à nossa espécie (animal?) como o fez/escreveu o próprio Kafka (apud DELEUZE; GUATTARI, 2015, p. 29): "Minha natureza símia escapava de mim rapidamente, ela escorria em cambalhotas, ainda que meu professor tenha se tornado ele mesmo simiesco e teve que renunciar às lições para entrar num asilo”. Essa (re)conexão se dá porque o ser humano estabelece limites políticos, étnicos e de gênero que condenam quem não quer/pode pertencer ao que se convencionou chamar de maioria. 
Em seu bestiário, Apollinaire, a um só tempo, dialoga com uma tradição medieval, porém a partir de um ponto de vista signatário das vanguardas em voga na Europa, e (re)inscreve o homem na espécie animal, o que podemos, grosso modo, designar como um processo de desterritorialização sistêmico-literária. A inflexão didática dos bestiários medievais, posta em cena para valorizar o homem como criação de Deus, sai do campo de visão de Apollinaire. Leiamos o poema “A cabra do Tibet” (APOLLINAIRE, 1997, p. 33):

Os pêlos da cabra e o tosão

Pelo qual bateu-se Jasão

Não valem nem parte do preço

Dos cabelos porque padeço.

Os versos sugerem, de modo ambíguo, a luta do argonauta Jasão tanto pela conquista do velocino de ouro (o tosão) quanto pela posse de Medéia (a cabra com seus pêlos). ${ }^{4}$ O próprio Jasão deve sua formação a Quíron, criatura meio homem, meio cavalo, filho de Cronos e de Filira (filha de Oceanos), que também educou Aquiles. Há nos versos de Apollinaire ingredientes que apresentam a experiência do amor, no caso ilustrado, enredado nas artimanhas do poder, do desejo e do engano. Chama-nos a atenção que o eu lírico compara seu sentimento àquele manifesto pelo argonauta educado por um ser entre o humano e o animal - o centauro - e que a amada daquele herói seja metamorfoseada em cabra nos versos.

\footnotetext{
${ }^{4}$ Segundo a mitologia clássica grega, Jasão foi enviado por Pelias, seu tio e usurpador do trono de Áison, pai de Jasão, para ser educado pelo centauro Quíron, numa manobra de afastamento do jovem sucessor do lugar que ele ocupava de modo espúrio. Retornado de seu convívio com Quíron, o jovem herdeiro é enviado pelo monarca ao reino de Colquis, a fim de reaver o velocino de ouro, artefato provavelmente dotado de propriedades mágicas. Para se aproximar do rei de Colquis e possuir o objeto, Jasão conta com a ajuda de Medéia, filha do monarca e dotada de poderes ligados à magia. Em fuga, ela teria matado o irmão. Posteriormente, assassinará Pelias, Glauce (amante de Jasão) e os dois filhos tidos com Jasão (HARVEY, 1987).

${ }^{5}$ Orfeu também teria participado da expedição do argonautas e seu canto ajudou os guerreiros a resistir às sereias. Ele desceu ao Hades, a fim de resgatar sua companheira Eurídice, morta pela picada de uma serpente. Sua missão não teve sucesso, pois ele se esqueceu da condição de não olhar para trás durante o percurso rumo à superfície. Orfeu foi despedaçado pelas Mênades, por interferir em seu culto. Sua trajetória lendária teria inspirado o orfismo, culto místico que "[...] ensinava a transmigração das almas e inculcava a pureza ritual e moral como único meio capaz de dar à alma sua liberação final para entrar na vida dos bem-aventurados” (HARVEY, 1987, p. 368)
} 
Vale ainda destacar sobre o bestiário de Apollinaire que ele tem como subtítulo “cortejo de Orfeu”. Orfeu 5 " "[...] é na mitologia o poeta por excelência, ele consegue seduzir as plantas, os animais, os homens e, se necessário, até mesmo os deuses, [...]” (FALEIROS, 1997, p. 17). Ele aparece como título de quatro poemas do Bestiário, costurando o amor a dois outros temas caros a esse conjunto poemático: a melancolia e a morte. Leiamos a segunda presença do poeta (en)cantador grego (APOLLINAIRE, 1997, p. 51):

\section{ORFEU}

Veja só este grupo infecto

Com cem olhos, pés aos milhares

Rotíferos, ouções, insetos

Micróbios bem mais singulares

Que os sete prodígios do mundo

E o palácio de Rosemundo!

Um sentido de abjeção está posto no verso inicial do poema - "Veja só este grupo infecto" -, com destaque para o qualificativo "infecto". Seligmann-Silva (2005, p. 39), tendo por base os estudos de Julia Kristeva, assevera que:

O abjeto, como manifestação do que há de mais primitivo em nossa economia psíquica, origina-se para ela [Kristeva] de um recalque originário, anterior ao surgimento do eu: o abjeto não é o objeto, é uma espécie de primeiro não-eu, uma negação violenta que instaura o eu; $[\ldots]$

No poema de Apollinaire, as imagens de grupos de animais microcóspicos - ouções/ácaros, os não-eus do eu do homem - sugerem a sobreposição, a prevalência da morte, alegorizada na sobrevivência de seres infinitesimais como os micróbios, sobre o amor terreno/humano, ainda que o mais apaixonado (como teria sido o dos amantes Rosemund e Henrique II e o de Orfeu e Eurídice). O caráter abjeto dos versos reside na violência de uma dupla lembrança (ancestral) do ser: o seu destino para a morte e a sua 
condição animal, desestabilizando os limites daquilo que se convencionou como ser próprio do humano em contraponto especialmente com o animal.

Assim, nosso interesse em chamar, para este breve estudo, o Bestiário de Apollinaire reside, particularmente, naquilo que denominamos anteriormente como processo de desterritorialização sistêmico-literária, uma dinâmica também encontrada em Animalescos, de Gonçalo Tavares. Essa dinâmica se presta a questionar a funcionalidade e o enfeixamento de categorias e de conceitos que existem nas relações humanas e em suas representações literárias, mas que resistem a uma nominação que dê conta do que eles sejam em sua totalidade.

Em entrevista a Luciano Trigo (2014/2018), respondendo à pergunta: "Que relação é possível estabelecer entre "Matteo perdeu o emprego" e os textos da série "O Bairro" e “O reino”? Há uma evolução?”, Tavares disse:

Para mim os meus livros são completamente diferentes, costumo usar a imagem de que cada livro é uma espécie de animal, um animal distinto. 'Matteo perdeu o emprego' poderia ser uma cobra, e não faz sentido dizer que uma cobra ou uma girafa é melhor do que um cão. Cada animal tem suas características, se quisermos rapidez pensamos no tigre, mas a tartaruga não é um animal pior do que o tigre. Então não vejo os livros como melhores ou piores, vejo como animais diferentes. Se queremos uma temática artística, devemos escolher um animal e não outro, um livro e não outro. Mas 'Matteo perdeu o emprego' é um livro muito distinto da série dos bairros, tem a ver com um ponto de vista mais lúdico e remete para um mundo paralelo, em uma espécie de utopia ficcional. Outros livros meus atiram mais para uma escrita mais realista, enquanto 'Viagem à Índia' é um livro que mistura poesia e prosa. 'Matteo...' mistura uma realidade totalmente absurda e uma segunda parte, de reflexão. O que eu sinto é que cada livro vai numa direção diferente, cada livro define um ponto, e vários livros permitem traçar uma linha. Não sei qual é esse desenho, nem o que ele está a representar, mas cada livro é um traço de um desenho, que é a obra que se vai construindo aos poucos.

Em linhas gerais, Gonçalo Tavares assevera que o mais importante em seus textos não é o gênero ao qual se encaixaria, porém o modo como o tema em foco é tratado. Vale 
destacar, ainda, a comparação que ele faz de seus livros com animais. Voltando para Animalescos, se por um lado, como já escrevemos, na ficha catalográfica da edição brasileira lemos a referência ao gênero conto, por outro, neste caso em específico, a fala de Tavares, quando comparada ao seu texto literário, é argumentável em favor de nossa proposição neste ensaio. Sem entrarmos na definição literária do seja o conto, optamos por percebêlo tão somente como um conceito.

Todo conceito existe em face de uma função/uma funcionalidade. Benoit HardyVallée reconhece duas funções para ele: a metafísica e a epistemológica, sendo esta última dividida em três outras: gnosiológicas, inferenciais e linguísticas. Como conceito, o conto cumpriria uma função metafísica, considerando que

A função metafísica de um conceito é estatuir sobre a verdadeira natureza de uma coisa, independentemente de nossa maneira de conhecê-la. [...]

É no sentido de que ele deseja ser uma descrição exata de uma parte do universo que função do conceito é metafísica. [...] O conceito tem, portanto, uma função normativa: especificar o que deve ser o caso, o que se traduz por duas funções metafísicas, a taxonomia normativa e a modalidade. (HARDY-VALLÉE, 2013, p. 100. Itálicos do autor)

A primeira função categoriza as coisas de modo adequado, classificando-as em face de suas marcas; a segunda justifica a possibilidade eleita. Ainda que nos defrontemos com dois aspectos aprioristicamente dinâmicos - adequação e possibilidade - do conceito, sua natureza é de (de)limitação. Segundo Alice Maria Araújo Ferreira (2013, p. 11),

[...] há um perigo no conceito, o de unir e de identificar, o que leva à perda da multiplicidade, da pluralidade, do movimento. Precisamos, então, ser criativos e criar conceitos capazes de falar dessa diversidade, da novidade, da sucessão de eventos. Tentar, incessantemente, dar conta do diferente para dar conta da multiplicidade de sentido e de seus movimentos.

Assim, mesmo que possamos duvidar da palavra do poeta, nas falas de Gonçalo Tavares (TRIGO, 2014/2018) sobre a importância das direções diversas de suas narrativas, 
detectamos um movimento criativo pela refacção constante da "máquina de gêneros" tentativa de agregar a dinamicidade dos gêneros à disposição da ficção. Mais do isso: o que lemos nos textos de Tavares argumenta em favor de sua assertiva na entrevista supracitada, especialmente, quando notamos sua inclinação para o ensaístico.

Desde o primeiro contato que tivemos com a obra de Tavares, por meio de Uma viagem à Índia, o que, à primeira vista, seria uma paródia de Os Lusíadas - o que Uma viagem também não deixa de ser - se tornou um itinerário nostálgico da impossibilidade do retorno, reterritorializando, para nós, tanto o conceito de epopeia quanto o de herói. Foi significativo o modo como pudemos (re)avaliar a presença das epopeias na literatura contemporânea e, para tanto, tivemos que (re)pensar o conceito do épico - e de outros gêneros - como ausência em constante (re)atualização a partir de uma memória semântica e não como memória absoluta como o faz, para tomarmos um exemplo literário, Ireneo Funes do conto de Jorge Luís Borges:

[Funes] Havia aprendido sem esforço o inglês, o francês, o português, o latim. Suspeito, contudo, que não era muito capaz de pensar. Pensar é esquecer diferenças, é generalizar, abstrair. No mundo abarrotado de Funes não havia senão detalhes, quase imediatos.

Não haver detalhes, leva-nos à repetição de fórmulas e à cristalização de ideias e de enunciados, inclusive, os ficcionais.

Retornando à função da taxonomia normativa da metafísica no que concerne ao conceito, abrimos nosso campo de visão para o ensaio "Taxonomias", parte do volume $O$ aberto, de Giorgio Agamben. Nele, Agamben se detém sobre as reflexões de Carl von Linnaues/Lineu, médico sueco do século XVII que em 1735 publicou a primeira edição do seu Systema Naturae, obra que inaugura a "Taxonomia Lineana" 7 .

\footnotetext{
${ }^{6}$ Referência ao livro de Alcir Pécora sobre textos do século XVII, entre eles, os sermões de António Vieira. ${ }^{7}$ As informações sobre Lineu foram colhidas em: BUCKERIDGE, Marcos. "Deus fez, Lineu organizou". Revista FAPESP, São Paulo, edição online, mar. 2008. Disponível em: < revistafapesp.br/2008/03/06/deus-fez-lineuorganizou/>. Acesso em: 3 out. 2017. A título de curiosidade, todas as pesquisas de Lineu foram subsidiadas pelo governo da Suécia.
} 
Em sentido geral, taxonomia é a "[...] ciência dos princípios e métodos de classificação dos diversos elementos de uma área científica” (COSTA, 2010, p. 1580). Lineu acreditava na criação humana como uma dádiva especial de Deus; ainda assim, éramos uma espécie em seu sistema, o Homo sapiens, do gênero Homo, inscrito na ordem dos Anthropomorpha. A epígrafe ao Systema Naturae diz: “Grande/magnífico é Deus Pai / E grande/magnífico é seu poder / E seu poder não é material".

Segundo Agamben (2017, p. 47),

Uma análise do Introitus que abre o Systema não deixa dúvidas quanto ao sentido que Linnaeus atribuía ao seu mote: o homem não possui nenhuma identidade específica senão a de poder reconhecer-se. Mas definir o humano não por meio de uma nota characteristica, mas por meio do conhecimento de si, significa que é homem aquele que se reconhece como tal, que o homem éo animal que deve reconhecer-se humano para sê-lo. (Os itálicos são do autor)

Ao que nos parece, o Homo sapiens, conforme posto por Lineu e lido por Agamben, não é uma espécie cuja definição seja claramente demonstrável. Ele, segundo Agamben (2017, p. 48), “[...] é, sobretudo, uma máquina ou um artifício para produzir o reconhecimento do humano". E como se produz esse (re)conhecimento? Cremos que por via da linguagem, que somente no século XIX passa a ser a marca privilegiada da espécie humana. ${ }^{8}$ Em “fenda na estrada / o pensamento / primatas" (TAVARES, 2016, p. 37), lemos:

[...] Nem sempre medita e analisa, o pensamento também vomita, e ei-lo a receber da parte fisiológica baixa o melhor dos apoios, as mãozinhas, por exemplo, que são iguais às dos primatas, batem nas costas do enjoado para que ele se sinta com presença amiga; [...].

O pensamento, que distinguiria o humano do animal, também adoece, freando suas atividades, no que é ajudado pelas mãos humanas, iguais às dos primatas; pensamento -

\footnotetext{
${ }^{8}$ Agamben esclarece seu leitor de que até o fim do século XVIII suspeitava-se que os pássaros falassem, havendo o depoimento de John Locke sobre o papagaio de Maurício de Nassau, que seria capaz de conversar e de responder a perguntas.
} 
homem - animal são colocados numa relação de paridade e de simultaneidade. Segundo Seligmann-Silva (2005, p. 41), ainda no rastro de Kristeva, "Se o corpo só se torna limpo com a perda da matéria fecal, essa separação reencena a separação originária”. Ao vomitar, o pensamento se alivia não por via anal, porém por via oral, pelas palavras, dizendo aquilo que está nas origens do animal humano.

Tomando a linguagem como traço distintivo entre o homem e o animal, Agamben (2017, p. 60), desta feita no ensaio "Máquina antropológica" do mesmo O aberto, tendo por base um texto do linguista alemão do século XIX Heymann Steinthal, adverte que a linguagem

[...] não é um dado natural já inscrito na estrutura psicofísica do homem, e sim um produção histórica que, como tal, não pode ser propriamente associada nem ao animal nem ao homem. Ao se suprimir esse elemento, a diferença entre o homem e o animal se anula [...].

Por outro lado, a linguagem, com sua função substantiva/nominativa, coloca o homem diante de dilemas afetivos, isto é, que o afetam como doença, como estigmas de ser humano e poder manifestar o que sente, atribuindo algum sentido a isso. Jacques Derrida (2002, p. 42-43) nos ensina, tendo por base Benjamin, que

Aquele que recebe um nome sente-se mortal ou morrendo, justamente porque o nome quereria salvá-lo, chamá-lo e assegurar sua sobrevivência. Ser chamado, escutar-se nomear, receber um nome pela primeira vez, é talvez saber-se mortal e mesmo sentir-se morrer. Já morto por estar prometido à morte: morrendo. (Como poder-seia, coloco a questão de passagem, recusar então o animal, assim privado de nominação, o acesso à experiência da morte enquanto tal?)

Ao saber-se esperando pela morte pelo ato da nominação, pelo mesmo processo o homem cria modos de se salvar, de ser superior entre os animais e entre outros homens, de matar simbolicamente. Em "cristo / uma casa” (TAVARES, 2016, p. 28-29), lemos:

Levanto-me para confrontar Cristo com as minhas razões. Deitome para confrontar Cristo com as minhas razões. Luto para confrontar Cristo com as minhas razões. Bocejo para confrontar Cristo com as minhas razões. Tenho fome para confrontar Cristo com as 
minhas razões. Excito-me para confrontar Cristo com as minhas razões. Atravesso a estrada, paro no passeio, digo adeus, faço um sinal obsceno com os dedos, subo para cima do telhado, finjo que escorrego, ladro com uma voz racional, vou de lá para cá cada vez mais rápido de tal maneira que o lá e o cá desaparecem e eu caio tão cansado porque destruí dois espaços ao mesmo tempo. Estou no solo e digo para fazerem uma casa, faço de parede e para quatro paredes faltam três homens. Chamo três amigos, eles recusam, chamo quem não conheço, há alguns curiosos, desses seleciono três

As razões humanas parecem não incomodar Cristo; ladrar com voz racional parece não incomodar nem animais, nem homens; o chamamento de três amigos para construir uma casa não é atendido. O eu narrativo não se deu conta, ainda, de que as formas de relacionamento entre homens, animais e Cristo são convencionadas, ou talvez tenha se dado conta, porém não sabe como se (com)portar em face da dinamicidade das relações sociais, religiosas e de linguagem e de suas formas de expressão.

Segundo Stephen Ullmann (1987, p. 37), existem diferenças entre os signos sistemáticos e os não sistemáticos: “Alguns signos, como, por exemplo, os gestos, não formam qualquer sistema coerente, enquanto que outros estão organizados segundo determinado modelo". Sobre a linguagem falada cotidiana, Ullmann (1987, p. 39) esclarece: "Muitas das palavras que usamos são convencionadas, enquanto que outras, termos onomatopaicos [...] são evidentemente icónicos”. Assim, tanto os gestos quanto as palavras faladas - e também as escritas - configuram-se como materialidade. Já seus significados são estabelecidos por uma correlação psíquico-memorialística. De retorno à narrativa "cristo / uma casa", perguntamo-nos: que memória terá Cristo dos gestos humanos? E de um ladrar racional?

Ainda que Gonçalo M. Tavares nos fale do continente europeu, não podemos nos esquecer de que sua voz nasceu em África/Angola. Explicitamente, ele não nos fala de África, porém não há como enxergar a presença violentadora do pai/colonizador na ação narrada em "espingarda / bala / o pai / plantas / animais / obrigar a natureza a acelerar" (TAVARES, 2016, p. 46):

nada de especial, um velho homem barbudo carrega uma espingarda, tem a arma atrás do ombro como um material de trabalhar a terra e até é: as balas são disparadas contra o solo, violentamente, e 
acredita-se que assim a colheita será melhor: as árvores, os frutos os cereais crescerão com estas sementes metálicas, sementes atiradas a grande velocidade contra o solo e a questão está mesmo na velocidade: é a velocidade que dá vida à natureza, a velocidade violenta da bala $[\ldots]$

A violência contra o solo - e nesse solo, devem germinar não somente seres vegetais, mas também homens e animais - não é nada de especial; ela se soma aos traços constitutivos do homem contemporâneo, configurando-se como mais uma das experiências humanas de crescimento e de dominação sobre o outro. No mesmo "espingarda / bala / o pai / plantas / animais / obrigar a natureza a acelerar” (TAVARES, 2016, p. 47-48), lemos:

[...] e se do céu não vem metal, da arma do pai vem, e muito, as balas sete oito nove ali estão, atiradas contra o solo, a cerca de um metro de distância, avança um passo, dois, e um tiro, mais dois passos e novo tiro; trata-se de semear, sem dúvida, o gesto é o mesmo, a intenção é a mesma, os efeitos são mais fortes, deus nos salve mas é assim que aprendemos a fazer crescer os animais, as plantas, os cereais, aqui tenho uma arma para obrigar a natureza a acelerar e utilizo esta ameaça e, se necessário, até outras de que me lembrei agora

Se a racionalidade humana da instrumentação bélica dá poder ao pai sobre o crescimento das coisas no mundo, por outro lado, há um Cristo dos animais que ameaça o homem com a ideia do embrutecimento animal pelo tédio em "floresta negra / animal alto / jesus dos animais / corredor de mil metros" (TAVARES, 2016, p. 67):

[...] estar muito tempo sem fazer nada, sem expectativas e sem medo e mesmo assim aguentam-se, não ficam loucos, não matam, um tédio excelente, o tédio que nos salva, e talvez seja este o segredo do Cristo dos animais, só te salvarás pelo tédio, pela falta de vontade, está sentado e sentado ficas, levantas-te e levantado ficas, olhas para o fundo por olhar e não por quereres ir para lá, estás bem onde estás e isso é deixar de ser humano, é passar a ser animal de quatro patas, mas é isto que o Cristo dos animais quer, humanos de quatro patas que estejam contentes, uma tribo de cem mil homens a quatro patas que se fascinem com os ponteiros dos relógios tal como os seus ancestrais se fascinavam com totens ou com a trovoada, ter tanto medo de um relógio como de um relâmpago, [...] 
Ao retirar Cristo de sua (con)vivência humana e de sua funcionalidade junto aos homens, o narrador de Tavares provoca no leitor um efeito de estranhamento, cuja qualidade por excelência é oferecer a possibilidade da variação, em face da invariabilidade das vivências cotidianas, cristalizadas, nesse caso, por uma tradição de orientação religiosa cristã.

A vivência do estranhamento oferecida pelas palavras de Tavares em Animalescos provoca o (des)conhecimento e o despertar de dúvidas e de afetos no sujeito. Gera-se, pois, uma expectativa - que pode ser satisfeita ou frustrada - quanto ao que virá mais adiante. Segundo Lausberg (1993, p. 112),

A poesia ${ }^{9}$ procura um estranhamento próprio e lúdico, que, dentro de seu género, lhe corresponda (dirigida ao pensamento estético) e a ele sacrifica a medida da credibilidade, a qual p.ex. (sic), o discurso jurídico é forçado a observar dentro do tribunal.

Não vem ao caso, dentro do projeto estético de Tavares, uma funcionalidade a priori do texto literário. Essa funcionalidade é um lugar de passagem (re)visitado de quando em quando pelo leitor, que é movido pela incompletude de sua invariável vida cotidiana. O que falta na vida desse sujeito? A grande questão não é o que falta, porém como ele busca preencher as lacunas de uma existência (mal) costurada (ainda) por ideias como progresso e evolução, marcadas por lapsos de tempo que chamaremos de tédio. Segundo Agamben (2007, p. 105),

[...] o homem que se entedia vem a se encontrar numa 'proximidade extrema' - ainda que aparentemente - do atordoamento animal. Ambos estão, em seu gesto mais próprio, abertos a um fechamento, integralmente entregues a algo que se recusa obstinadamente [...]

${ }^{9}$ Aqui tomamos a expressão poesia no sentido mais amplo de poiesis/criação, fazer literário. 
E ao que o homem se recusa? Talvez ele se recuse a (re)assumir sua condição (de) animal que, em suspensão, se abala e busca novos voos. Esses voos e sobrevoos podem ser oferecidos pela obra de arte, no caso deste ensaio, pela leitura de Animalesccos.

\section{ANIMALESCOS, EL BESTIARIO CONTEMPORÁNEO DE GONÇALO M. TAVARES}

RESUMEN: Considerado un género literario medieval, el bestiario describía física y comportamentalmente animales reales o imaginarios, atribuyendo un cuño moralizante al cuadro representado. Era escrito en prosa o versos, siendo ilustrado y tomando la naturaleza al modo cristiano de ver el mundo, es decir, como fuente de enseñanza para el ser humano, demostrando a veces su parentesco no sólo biológico con el animal. Con el distanciamiento del universo secular de los dogmas cristianos, los bestiarios pierden su fuerza como género, y los animales de sus páginas migran a la iconografía eclesiástica y, más tarde, a las artes visuales, valiendo citar, por ejemplo, la relación visual entre hombres y animales en la obra de Goya. Nuestra pretensión es demostrar que Animalescos, de Gonçalo M. Tavares, se agrega al género bestiario, que no desapareció, sin embargo, ganó nuevos contornos con el paso de los tiempos. Si en la ficha cartográfica de la edición brasileña (Dublinense, 2016) se lee que se trata de "contos portugueses", no estamos de acuerdo con esa rúbrica, ya que hay un hilo temático - la perversidad - que se alinea en las narrativas, basadas en las relaciones entre hombres, animales, ciudades, máquinas, neurosis, violencia y muerte.

PALABRAS-CLAVE: Bestiario; Géneros Literarios; Abierto; Literatura Portugués.

\section{REFERÊNCIAS}

AGAMBEN, Giorgio. O aberto. O animal e o homem. Tradução Pedro Mendes. 2. ed. Rio de Janeiro: Civilização Brasileira, 2007. (Sujeito e História).

APOLLINAIRE, Guillaume. O bestiário on cortejo de Orfeu. Tradução Álvaro Faleiros. São Paulo: Iluminuras, 1997.

BORGES, Jorge Luis. Funes, o memorioso. Tradução Marco Antonio Franciotti. Disponível em: < http://www.gradadm.ifsc.usp.br/dados/20141/SLC0630-1/Funes,\%20o\%20 Memorioso.pdf>. Acesso em: 30 mar. 2018.

COSTA, Margarida Faria da (coord.). Grande dicionário da Lingua Portuguesa. Porto: Porto Ed., 2010.

DELEUZE, Gilles; GUATTARI, Félix. Kafka: por uma literatura menor. Tradução Cíntia Vieira da Silva. Belo Horizonte: Autêntica, 2015. (Filô/Margens). 
DERRIDA, Jacques. O animal que logo sou. Tradução Fábio Landa. São Paulo: Editora UNESP, 2002.

FALEIROS, Álvaro. Notícias do Bestiário. In: APOLLINAIRE, Guillaume. O bestiário ou cortejo de Orfeu. Tradução Álvaro Faleiros. São Paulo: Iluminuras, 1997. p. 9-22.

FERREIRA, Alice Maria Araújo. Prefácio. In: HARDY-VALLÉE, Benoit. Que é um conceito? Tradução Marcos Bagno. São Paulo: Parábola, 2013. p. 7-12.

HARDY-VALLÉE, Benoit. Que é um conceito? Tradução Marcos Bagno. São Paulo: Parábola, 2013. (Episteme).

HARVEY, Paul. Dicionário Oxford de literatura clássica grega e latina. Tradução Mário da Gama Kury. Rio de Janeiro: Jorge Zahar Ed., 1987.

LAUSBERG, Heinrich. Elementos de retórica literária. Traduçao R. M. Rosado Fernandes. 4. ed. Lisboa: Calouste Gulbenkian, 1993.

MARZANO, Michela (org.). Dicionário do corpo. Tradução de Lucia Pereira de Souza et al. São Paulo: Loyola; Centro Universitário São Camilo, 2012.

SELIGMANN-SILVA, Márcio. Do delicioso horror sublime ao abjeto e à escritura do corpo. In: O loca da diferença: ensaios sobre memória, arte, literatura e tradução. São Paulo: Ed. 34, 2005. p. 31-44.

TAVARES, Gonçalo M. Animalescos. Porto Alegre: Dublinense, 2016.

TRIGO, Luciano. Gonçalo M. Tavares: 'O meu trabalho é iluminar palavras”. Entrevista, 2014. Disponível em: <http://g1.globo.com/platb/maquinadeescrever/2014/02/09/gon calo-m-tavares-o-meu-trabalho-e-iluminar-palavras/>. Acesso em: 30 mar. 2018.

ULLMANN, Stephen. Semântica - Uma introdução à ciência do significado. Tradução J. A. Osório Mateus. 5. ed. Lisboa: Fundação Calouste Gulbenkian, 1987.

Recebido em: 18/05/2018.

Aprovado em: 16/07/2018. 